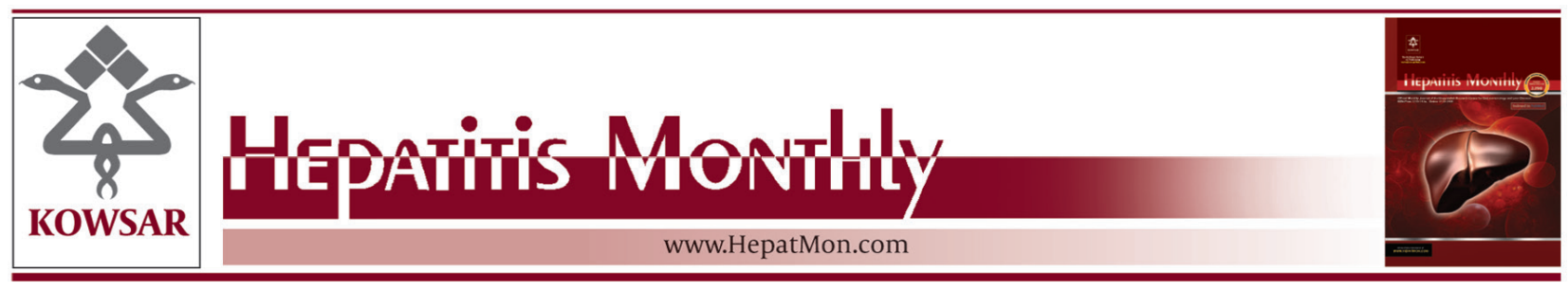

\title{
Neuropsychiatric and Psychosocial Issues of Patients With Hepatitis C Infection: A Selective Literature Review
}

\author{
Amirhossein Modabbernia ${ }^{1,2}$, Hossein Poustchi ${ }^{1}$, Reza Malekzadeh ${ }^{1, *}$ \\ ${ }^{1}$ Digestive Disease Research Centre, Shariati Hospital, Tehran University of Medical Sciences, Tehran, IR Iran \\ 2 Psychiatric Research Centre, Roozbeh Hospital, Tehran University of Medical Sciences, Tehran, IR Iran \\ * Corresponding author: Reza Malekzadeh, Digestive Disease Research Centre, Shariati Hospital, Tehran University of Medical Sciences, 14117, Tehran, IR Iran. \\ Tel.: +98-2182415000, Fax: +98-2182415400, E-mail: malek@ams.ac.ir.
}

\begin{abstract}
A B S T R A C T
Context: We briefly reviewed the evidence on the association of hepatitis $\mathrm{C}(\mathrm{HCV})$ infection with several aspects of mental and psychosocial health.

Evidence Acquisition: Medline was searched with appropriate keywords. The primary sources were the systematic reviews. If systematic reviews were not available for a subject, then the most relevant and methodologically sound original studies were selected.

Results: HCV infection is associated with poorer health-related quality of life, and physical, mental, and social health. A part of impaired health of these patients is related to cirrhosis, intravenous drug use, co morbid psychiatric disorders, stigmatization, poor social support, alcohol abuse, and interferon treatment. However, HCV itself is also associated with poorer health status particularly in the physical and cognitive domains, which might be related to brain alterations induced by the virus. Interferon treatment is an important cause of depression in HCV patients and sometimes is associated with irritability, manic episode, or acute confusional state. Social health of HCV patients is significantly impaired by stigmatization, poor social support, psychiatric comorbidties, and impaired coping. Psychosocial impairment of HCV patients significantly impairs their treatment adherence. A supportive and nonjudgmental multidisciplinary team is required for optimal management of these patients.

Conclusions: Patients with HCV infection had complex neuropsychiatric and psychosocial problems. These problems are challenges for management of HCV infection, affect the patient's care significantly, and might alter the course of the disease. A multidisciplinary approach, a supportive environment, and a nonjudgmental healthcare team are required for optimal medical and psychosocial management of patients with HCV.
\end{abstract}

Keywords: Anxiety; Depression; Fatigue; Hepatitis C; Mental Health; Neurobehavioral Manifestations; Social Stigma

Copyright () 2013, Kowsar Corp.; Published by Kowsar Corp.

Article type: Review Article; Received: 01 Aug 2012, Revised: 20 Aug 2012, Accepted: 08 Oct 2012; DOI: 10.5812/hepatmon.8340

-Implication for health policy/practice/research/medical education:

Patients with HCV infection had a complex of neuropsychiatric and psychosocial problems. These problems are challenges for management of HCV infection, affect the patient's care significantly, and might alter the course of the disease. A multidisciplinary approach, a supportive environment, and a nonjudgmental healthcare team are required for optimal medical and psychosocial management of patients with HCV. Research efforts should focus on longitudinal studies of effect of disease and treatment on several aspects of patients' lives and a more in-depth exploration of psychosocial issues of HCV-infected patients.

Please cite this paper as:

Modabbernia A, Poustchi H, Malekzadeh R. Neuropsychiatric and Psychosocial Issues of Patients With Hepatitis C Infection: A Selective Literature Review. Hepat Mon.2013;13(1):e8340. DOI: 10.5812/hepatmon.8340

Copyright (C) 2013, Kowsar Corp.; Published by Kowsar Corp.

This is an Open Access article distributed under the terms of the Creative Commons Attribution License (http://creativecommons.org/licenses/by/3.0), which permits unrestricted use, distribution, and reproduction in any medium, provided the original work is properly cited. 


\section{Context}

In the present paper, we briefly review the essential evidence on the association of HCV infection with several aspects of mental and psychosocial health of the patients. This review primarily aimed to inform the clinicians and the researchers about this broad and important area of management of patients with HCV. For those readers who are interested in the details of each problem appropriate references are introduced.

\section{Evidence Acquisition}

Medline was searched with keywords: HCV, hepatitis C, psychological, psychosocial, quality of life, depression, anxiety, fatigue, anger, irritability, mental health, physical health, cognition, cognitive, stigma, psychiatric, psychiatry, mood, behavior, addiction, habits, coping, stress, social support, pain, fibromyalgia. The primary sources for the review were systematic reviews. If systematic reviews were not available for a subject, the most relevant and methodologically sound original studies were selected.

\section{Results}

Hepatitis C virus (HCV), an RNA-virus which primarily infects liver parenchyma is currently a major health problem $(1,2)$. It is associated with chronic liver disease, cirrhosis, and hepatocellular carcinoma and imposes a huge burden on the health care programs and the society. In addition to its impact on liver, patients with HCV encounter problems in a wide variety of health areas including health related quality of life (HRQOL), and mental and physical health $(3,4)$. Importantly, to reduce the imposed burden of the disease, an important step is to evaluate and manage these factors in an appropriate manner. While some of these health problems are attributable to the factors which generally accompany HCV (such as addiction or personality problems), a growing body of evidence suggest that they might be related to the HCV itself.

\subsection{HRQOL}

HCV negatively affects the HRQOL of patients (5). A systematic review of 32 studies assessed the impact of HCV infection on HRQOL. Analysis of 15 studies comparing HCV patients versus healthy controls indicated diminished HRQOL in HCV patients with a moderate to large effect size. Furthermore, it was found that HCV most prominently affected social and physical functioning, general health and vitality. The review also showed that HRQOL was better in patients who achieved sustained virological response (SVR) than in those who did not, with more impact on the general health and role-physical subscales. The study also suggested that small histopathological or biochemical changes were unlikely to af- fect HRQOL. However, cirrhosis significantly diminished HRQOL of the patients with HCV (6). A recent systematic review of 66 studies provided rather consistent evidence of reduced HRQOL in untreated HCV patients (7). Results of the same review demonstrated reduced HRQOL during the treatment and improved HRQOL post-treatment. Improved post-treatment outcomes were particularly prominent in the patients with SVR. In addition to the impact of treatment, several other factors affect HRQOL in HCV-infected patients. Several studies have found that a part of the reduction in HRQOL can be explained by substance addiction, cirrhosis, and other comorbidities (8). However, there is a strong line of evidence that HRQOL is impaired in HCV patients even when these factors are controlled (9-11). HCV seems to differ from its hepatitis $\mathrm{B}(\mathrm{HBV})$ counterpart in affecting the health of the individual by more profound effect on HRQOL, and mental and physical health $(1,9-15)$. In a recent study comparing HRQOL between HBV and HCV patients after controlling several related factors such as addiction, alcohol, severity of liver disease, etc. the authors found strong evidence for the relationship of HCV infection with impaired physical health (9). Importantly, in a separate study the same authors also found inverse association between the levels of brain-derived neurotropic factor (BDNF) to physical health in patients with HCV but not HBV infection (11). BDNF is a neurtophic factor which is produced by several body tissues (most importantly brain) and is important in neuronal development and differentiation. Mentioned findings together with the evidence of cognitive dysfunction and brain involvement in HCV strongly raise the possibility that health problems in these patients are associated with direct effect of HCV on brain (11, 14-19). A review of the studies on the effect of liver transplantation (OLT) on HRQOL in patients with HCV concluded that OLT generally improved the HRQOL scores in these patients, particularly in social functioning and physical health domains. However, these patients still had significantly poorer HRQOL (particularly in psychological domains) than healthy controls. Indeed, OLT had little effect on long-term psychological improvement. This was in contrast to pre-OLT state in which the psychological scores (but not other domains of health) of the patients were closer to the general population. Importantly, knowledge of the HCV recurrence significantly reduced the HRQOL in patients following OLT (20).

\subsection{Fatigue and Psychosomatic Symptoms}

Fatigue is probably the most common extra hepatic manifestation of HCV infection with a prevalence of around 50\% (21). Most studies have shown higher fatigue levels in the patients with HCV compared with patients with HBV infection and healthy controls (22). The impaired physical health of patients with HCV has been replicated using a wide variety of HRQOL and fatigue measures. Chronic fatigue syndrome (CFS) is unrelated 
to HCV infection and is generally severer than the fatigue experienced by HCV-infected patients (23). Fatigue in HCV is of central type and is associated with cognitive impairment and depression. Psychological and psychiatric comorbidities as well as old age, being female and single have been important predictors of fatigue in several studies $(9,24,25)$. Several biological markers including low serum carnitine, creatinine, and BDNF concentrations ( 9 , 11, 26), and higher serum leptin concentrations (27) also predicted higher fatigue levels in HCV-infected patients. Other biochemical, pathological, and viral parameters are unrelated to fatigue $(9,21,27,28)$. An important correlate of fatigue in HCV-infected individuals is HCV itself $(9,11)$. Fatigue was substantially improved following SVR after antiviral treatment (28). IFN-induced fatigue in HCVinfected individuals is associated with some molecular signatures of inflammatory pathways such as cAMP responsive element binding protein/activation transcription factor (CREB/ATF) and p38 mitogen activated protein kinase (MAPK) (28-30). Several treatment options such as ondansetron, exercise, modafinil, armodafinil, amantadine and acetyl L-carnitine have been used successfully for management of HCV-induced fatigue (22, 28-34).Other physical symptoms associated with HCV infection are arthralgia, fibromyalgia, myalgia, and chronic pain which together have been reported in more than half of the patients in some series $(21,24,35-39)$.

\subsection{Psychiatric Disorders}

HCV is one of the few infections, in addition to HIV, which is heavily linked to psychiatric disorders (40, 41).A cause for this strong association is that illicit drug injection (IDU) is the most important risk factor for HCV infection. Drug injection is common in the patients with personality problems, besides other high risk behaviors (alcoholism, sexual high risk behaviors), and mood disorders (42). Even among non-injection drug users, up to $30 \%$ might be infected with HCV (43). Among all abused substances alcohol is the only one that can boost the progression of the liver involvement and therefore should be taken very seriously. United States veterans have been most widely studied regarding the prevalence of trimorbidity (HCV, substance abuse and psychiatric illness). In the largest study on veterans, $85 \%$ of 33842 tested individuals had evidence of past or present psychiatric disorders or substance abuse, and more than $60 \%$ of them had comorbid substance abuse and psychiatric disorders (44). However, in non-veteran patients the rates of psychiatric disorders have been much lower $(45,46)$. Alcoholism is associated with higher prevalence of anti-HCV antibody positivity. Alcohol acts synergistically with HCV to deteriorate the liver disease and reduces the treatment response to Interferon (IFN) primarily by decreasing the compliance (47). IFN-alpha is increasingly being used for HCV treatment. Besides its beneficial effects, IFN alpha may induce a variety of neuropsychiatric side effects such as acute confusional state, depressive syndrome, and agitated manic episode (48). Following IFN treatment of patients with $\mathrm{HCV}$, up to $70 \%$ may develop depression (41). Several mechanisms have been proposed for this association including altered monoamine metabolism (41), increased rate of apoptosis (49), BDNF reduction (50), and altered hypothalamus-pituitary-adrenal axis function (48). In a meta-analysis of 26 observational studies, the authors concluded that one fourth of patients who underwent treatment with interferon and ribavirin, developed major depressive disorder (MDD). High baseline serum interleukin 6 concentrations, being female, history of psychiatric disorder, sub-threshold depressive symptoms, and low educational level significantly predicted the occurrence of MDD during antiviral treatment (51). Neurovegetative/somatic symptoms of depression occur early in the course of IFN therapy, whereas cognitive/mood symptoms often become evident after the fourth week of treatment (41). Depression, anxiety, and cognitive complaints are responsive to serotonergic antidepressants, whereas neuro-vegetative symptoms such as decreased appetite, fatigue, sexual impairment, and psychosomatic symptoms are less responsive to SSRIs (52). Neurovegetative symptoms can be better managed with serotoninnorepinephrine reuptake inhibitors, bupropion, methylphenidate or modafinil (48). In a systematic review of 64 observational and interventional studies, the authors showed that SSRIs might be the first choice for treatment of interferon-induced MDD (53). IFN alpha-induced acute confusional states present with psychomotor retardation, disorientation, Parkinsonism, and psychosis. IFN alpha is also capable of inducing manic symptoms. Severe mania which can occur as a result of IFN administration should be treated with immediate discontinuation of IFN and antidepressants and initiation of a mood stabilizer (48). A recent retrospective study on 910 patients with HCV compared the rate of psychiatric complications during the treatment with IFN between patients with bipolar disorder, patients with MDD, and patients without psychiatric illness. Psychiatric complications occurred in more than half of the patients with MDD or bipolar disorder and one third of the patients without psychiatric illness. However manic episode occurred only in one out of 38 patients with bipolar disorder. Therefore, it was concluded that patients with bipolar disorder who were selected carefully can achieve successful treatment outcomes comparable to those in patients without bipolar disorder (54). Specific risk factors for IFN-induced suicide are unknown yet (41). European Expert Consensus Statement has recently released a guideline for management of mental health disturbances associated with IFN treatment. According to the Consensus, before starting the antiviral treatment, a complete psychiatric history should be taken, and information regarding psychiatric adverse effects should be given. Following initiation of the antiviral treatment, mood status should be assessed 
every four weeks in the first three months of treatment and then at least every 12 weeks after the end of the treatment. The intervals between two monitoring visits should be halved in the case of psychiatric comorbidity or substance abuse. Patients with psychiatric comorbidity or substance abuse do not generally differ in their treatment outcomes from other patients. However, the Consensus suggested acute and major psychiatric disorders and acute ongoing and uncontrolled IV drug abuse as relative contraindications to antiviral treatment. The Consensus recommended citalopram as firs-line treatment for IFN-induced depression. Antidepressant treatment should be continued for at least 12 weeks following the end of IFN treatment. Antidepressant treatment is also indicated for those patients with baseline depressive symptoms and for those with history of IFN-induced depression. Treatment with antidepressants is generally not recommended for all HCV patients and should be used on an individual basis (41). Not only IFN itself is associated with depression, but it seems that HCV might also be associated with mood problems. Again, a part of this link can be explained by HCV-accompanied factors (such as personality problems, high-risk behavior, stigma, and substance abuse). However, there is evidence that some specific genotypes of HCV such as 3 a might be associated with increased risk of depression $(9,55)$. Evidence of HCV neuro invasion may be another explanation for the association between mental disorders and $\operatorname{HCV}(9,55)$. Anxiety disorders in patients with HCV seem to parallel depressive disorders in prevalence rates. Using Structured Clinical Interview for DSM-IV Axis I (SCID-I) in a sample of 500 patients with $\mathrm{HCV}$, prevalence of any depressive disorder, MDD, generalized anxiety disorders, and panic disorders were $18.2 \%, 6.4 \%, 7.0 \%$ and $5.8 \%$ respectively (56).

\subsection{Sleep Problems}

In a review, Sockalingam et al. (57) addressed the sleep disturbances in HCV. Around $60 \%$ of patients with HCV may suffer from sleep disturbances due to various reasons including comorbid psychiatric disorders, substance abuse, and advanced liver disease. There is evidence for increased rate of sleep disruption, obstructive sleep apnea, and probably restless leg syndrome in patients with HCV. One fifth to one third of the individuals being treated with pegylated or conventional IFN experience sleep problems. The mechanisms proposed for IFNinduced sleep disturbances are inflammatory cytokines, altered serotonin metabolism, and modulation of narcolepsy related gene. Importantly, sleep disturbances prior to IFN treatment is a risk factor for treatment-emergent depression. Treatment of sleep problems in HCV consists of sleep hygiene, sleep-promoting agents such as antihistamines, probenzodiazepines (such as zolpidem, zaleplon), and sedative antidepressants (trazodone, mirtazapine) for insomnia, modafinil for hypersomnia, and gabapentin and iron replacement for restless leg syn- drome $(57,58)$.

\subsection{Neuropsychological Dysfunction}

Several studies have reported evidence of cognitive dysfunction in patients with HCV. Although cognitive dysfunction is seen in hepatic encephalopathy as well, the nature of the condition is different from what is seen in patients with HCV without hepatic encephalopathy. Many patients with HCV suffer from impaired concentration and memory, a condition which is called "brain fog" (59). Impairment of concentration, sustained attention, attentional processing, working memory, and visuomotor processing speed have been reported in HCV-positive patients $(15,18,60,61)$. A recent interesting study has provided evidence for decision-making dysfunction in patients with HCV with a bias toward smaller immediate rewards rather than larger delayed rewards (62). In general, constructional abilities and non-verbal recall is intact in these patients (60). Electrophysiological studies have also shown evidence of cognitive dysfunction in HCV positive patients $(19,63)$. Prepulse inhibition (PPI) which reflects the function of forebrain cortico-striatialpallidal-thalamic circuit maybe a useful and sensitive measure of attentional processing deficits in HCV patients (64). Moreover, comparison of HCV with HBV infected patients has shown poorer visuo-spatial memory performance in HCV subjects (65). Studies in specific populations of HCV patients such as women, children, and those without substance abuse history $(66,67)$ have also demonstrated evidence of cognitive dysfunction in these patients. In a review, Perry et al. (67) evaluated four possible mechanisms for cognitive dysfunction in patients with HCV. Premorbid characteristics and habits (particularly substance abuse) could not explain the cognitive dysfunction in these patients, because patients without such habits still showed various levels of cognitive impairment. Moreover, psychiatric disorders were not associated with cognitive problems in most of the studies. A third explanation is virus invasion of the brain, which although present does not contribute very much to the process of cognitive dysfunction. The last explanation given by Perry and colleagues is the activation of the brain inflammatory system by the virus. In addition to these explanations, the current study group has recently shown reduction of BDNF levels in the serum of these patients (67). Although the cognitive processes of the patients were not studied, it was shown that fatigue (which is usually of central type in patients with HCV) was inversely related to BDNF levels. Although no one has studied the relation between cognition and BDNF in the patients with $\mathrm{HCV}$, an association between the two seems likely (11). Furthermore, two important factors that might exacerbate cognitive impairment of $\mathrm{HCV}$ patients are coinfection with HIV and INF (but not low dose peg interferon) treatment $(64,68)$. In a study, following treatment with INF/ribavirin, the patients who were classified as 
SVR showed reduced brain inflammation/infection and improved neuropsychological function compared with the patients who were non-responders (69).

\subsection{Neurological Involvement}

Neurological complications of HCV infection are uncommon. In a review, Monaco et al. (70) identified various types of CNS involvement in HCV-infected individuals. These included acute cerebrovascular accidents, CNS vasculitis, encephalopathic syndromes, white matter involvement, inflammatory disorders of CNS, and peripheral neuropathy (70).

\subsection{Evidence of Brain Involvement}

Substantial evidence of reduced mental and physical health and impaired cognition has led to this hypothesis that HCV can affect brain function. The brain dysfunction in HCV is largely unrelated to substance abuse, INF treatment, disease severity, and hepatic encephalopathy (71). There are several lines of evidence which suggest brain changes in HCV-positive patients. Neuroimaging studies have shown strong evidence for brain alterations particularly of basal ganglia in patients with $\mathrm{HCV}(46)$. Moreover, both dopaminergic and serotoninergic dysfunctions have been demonstrated in the brain of HCV-infect individuals (72).Fletcher and McKeating reviewed the evidence on the HCV involvement of the brain. PCR-based methods provided evidence for the presence of HCV RNA (including negative-strand intermediate which has replicative role) in the brain of individuals with HCV infection. Moreover, both neuroimaging and post-mortem studies have shown evidence of microglial and inflammatory activation in patients with HCV (59).

\subsection{Effect of HIV-HCV Comorbidity on Psychosocial Aspects of Life}

Substance abuse and HIV-HCV co-infection frequently concur in a single patient. All of these conditions can have deleterious effect on psychosocial health of the patients. Martin-Thormeyer et al. (73) have reviewed the impact of these comorbidities on the psychosocial health of the patients. Because of similar routes of transmission, up to $90 \%$ of patients might have con-infection according to some European series. HRQOL of the HIV-HCV co-infected individuals is poorer than those of HIV-infected or HIV-HBV co-infected individuals according to the review. Depression, fatigue, and substance abuse are important predictors of poorer HRQOL in HIV-HCV co-infected patients. Decreased processing and psychomotor speed in co-infected individuals compared with those of monoinfected individuals have been reported in several studies (33). However not all studies showed poorer cognitive functioning in HIV-HCV co-infected individuals including a large study on more than 1000 women (74).

\subsection{Psychosocial Experience of Living with $\mathrm{HCV}$}

In a narrative systematic review, Miller et al. (7) identified 43 studies on this subject, all of which had been conducted in Western countries. HCV diagnosis was found to have deteriorating effects on social functioning in most of the studies. The authors also concluded that HCV was associated with social marginalization, impairment of intimate and family relationships, reduction in substance and alcohol abuse, changes in dietary intake, reduced sense of well-being due to fear of transmission and prognosis, fatigue, hopelessness, depression, anger, and stigma (7).

\subsection{Anger and Irritability}

Anger and irritability are important but underestimated side effects of INF treatment. In a review of ten studies on the effect of antiviral treatment on irritability, up to $75 \%$ of the patients experienced irritability following treatment (75). Irritability might be secondary to other mood disorders which often arise during antiviral treatment. Anger/irritability during antiviral treatment has been linked to TNF-alpha polymorphisms but not serotonin transporter polymorphism (76). Prolactin was also associated with anger in HCV patients in one study (77).

\subsection{Stigma}

In a concept analysis, stigma in the context of HCV was defined as a subjective and variable, perceived (usually) negative phenomenon. From this point of view, stigma has interrelated intrapersonal, interpersonal and structural dimensions (78). A distinctive aspect of the HCV-related stigma is its relation to IDU (78). Stigma negatively affects the HRQOL, mental health, and social life of the patients, and leads to difficulties with receiving or accepting treatment $(79,80)$. Poor social and work adjustment, lower acceptance of the illness, and higher subjective complaints are other problems associated with stigmatization (81). Studies showed that women generally experienced more stigmatization $(80,82,83)$. In different series from $35 \%$ to more than $85 \%$ of the patients with HCV were reported to experience stigma $(80,84,85)$. Stigma can occur as a result of discrimination. In an Australian study on over 500 patients with HCV, $65 \%$ of the patients reported discrimination which most commonly had occurred in the healthcare setting (101).

\subsection{Coping}

Coping is the individual cognitive and behavioral response to perceived stress. In a study on over 100 individuals with HCV, the most commonly used coping style was problem-solving behavior followed by distraction and self-revalorization, religiousness and search for meaning, cognitive avoidance and dissimulation, and depressive coping. Importantly, recent diagnosis was associated 
with the highest levels of problem-solving behavior and the lowest levels of depression. Other factors such as mode of acquisition were found unlikely to affect the coping styles used (86). Several studies have reported using inappropriate coping strategies in patients with HCV which may negatively affect several aspects of their management (87-89).

\subsection{Social Support}

Social support is an important aspect of the lives of the HCV-infected individuals. In a study of 340 patients with HCV infection, $45 \%$ noted the loss of at least one relationship following diagnosis of infection (90). Studies have shown evidence of low social support in HCV-infected patients and its association with living alone, being unemployed, poorer HRQOL, exclusion from antiviral therapy, physical symptoms, psychiatric comorbidities, and IDU $(65,90-93)$. Therefore, support groups may improve health outcomes in patients living with chronic HCV infection (94).

\subsection{Psychosocial Barriers to the Treatment}

Providing care to the patients with HCV is a complex process because of characteristics of the patients, the disease, health care workers, and the system $(95,96)$. In a study, two third of the HCV patients declined treatment because of asymptomatic nature of their infection together with concerns regarding treatment side effects (97). In over one third of the patients with HCV who do not receive treatment the reason is psychosocial (98). An important aspect of the care for these patients comprises management of mental health problems and in particular intravenous drugs use (IDU). The patients who abuse substance should be treated with patience and tolerance in a mutual and trusting relationship with their provider. Many patients have had negative experiences with judgmental and unresponsive health-care system, and therefore must be treated in a respectful, nonjudgmental, and supportive manner (95). Poverty, fear of arrest, social isolation, involvement in unstable primary care relationship, discrimination, several comorbidities, unavailability of expertise, and high expenses of the management all add to the complexity of care in these patients $(79,95,96)$. Moreover, physicians frequently attribute the treatment failure to drug addiction, and thus many are reluctant to see addicted patients (99). A client-centered approach in a multidisciplinary team is probably the best way to increase the rate of treatment satisfaction and thus adherence in $\mathrm{HCV}$ patients with drug addiction (95). Edlin et al. (95) reviewed principals of care in these patients. An issue of raising concern is stopping or withdrawing optimal treatment of HCV because of psychiatric complications. In a retrospective study conducted in Minnesota, USA 101 physicians who were treating patients with chronic HCV were interviewed. One in five patients had not received optimal management of HCV due to a psychiatric problem, and less than half of the physicians were collaborating with psychiatry or psychology experts (100). This rate is probably much higher in the setting of crowded HCV clinics in third world countries. On the other hand, it has been shown that patients with optimal psychiatric management adhere more strictly to their antiviral regimen than those patients without (101). Considering several studies together, Loftis et al.(96) have shown that little evidence supports withholding treatment from eligible patients with HCV and comorbid substance abuse (other than alcohol) or psychiatric disorders. However, these patients should be closely monitored for psychiatric side effects of treatment and be actively treated for their mental illness (96).

\section{Conclusions}

Patients with HCV infection had complex neuropsychiatric and psychosocial problems. These problems are challenges for management of HCV infection, affect the patient's care significantly, and might alter the course of the disease. A multidisciplinary approach, a supportive environment, and a nonjudgmental healthcare team are required for optimal medical and psychosocial management of patients with HCV.

\section{Acknowledgements}

None declared.

\section{Authors' Contribution}

Study concept and design: Malekzadeh, Modabbernia, and Poustchi. Searching the literature and writing the first draft: Modabbernia. Critical revision of the manuscript for important intellectual content: Poustchi and Malekzadeh.

\section{Financial Disclosure}

None declared.

\section{Funding/Support}

None declared.

\section{References}

1. Bonkovsky HL, Snow KK, Malet PF, Back-Madruga C, Fontana RJ, Sterling RK, et al. Health-related quality of life in patients with chronic hepatitis $\mathrm{C}$ and advanced fibrosis. $J$ Hepatol.2007;46(3):420-31.

2. Ghany MG, Strader DB, Thomas DL, Seeff LB. Diagnosis, management, and treatment of hepatitis C: an update. Hepatology.2009;49(4):1335-74.

3. Crone C, Gabriel GM. Comprehensive review of hepatitis C for psychiatrists: risks, screening, diagnosis, treatment, and interferonbased therapy complications. J Psychiatr Pract. 2003;9(2):93-110.

4. Forton DM, Thomas HC, Taylor-Robinson SD. Quality of life and cognitive function in chronic hepatitis $\mathrm{C}$ - what to measure? J Hepatol. 2003;39(2):272-4. 
5. Foster GR. Quality of life considerations for patients with chronic hepatitis C. J Viral Hepat. 2009;16(9):605-11.

6. Spiegel BM, Younossi ZM, Hays RD, Revicki D, Robbins S, Kanwal F. Impact of hepatitis $C$ on health related quality of life: a systematic review and quantitative assessment. Hepatology. 2005;41(4):790-800.

7. Miller ER, McNally S, Wallace J, Schlichthorst M. The ongoing impacts of hepatitis c - a systematic narrative review of the literature. BMC Public Health. 2012;12(1):672.

8. Amodio P, Salari L, Montagnese S, Schiff S, Neri D, Bianco T, et al. Hepatitis $C$ virus infection and health-related quality of life. World J Gastroenterol. 2012;18(19):2295-9.

9. Ashrafi M, Modabbernia A, Dalir M, Taslimi S, Karami M, Ostovaneh MR, et al. Predictors of mental and physical health in non-cirrhotic patients with viral hepatitis: A case control study.J Psychosom Res. 2012;73(3):218-24.

10. Foster GR, Goldin RD, Thomas HC. Chronic hepatitis C virus infection causes a significant reduction in quality of life in the absence of cirrhosis. Hepatology. 1998;27(1):209-12.

11. Modabbernia A, Ashrafi M, Keyvani H, Taslimi S, Poorkaveh A, Merat S, et al. Brain-derived neurotrophic factor predicts physical health in untreated patients with hepatitis C. Biol Psychiatry. 2011;70(5):e31-2.

12. Bondini S, Kallman J, Dan A, Younoszai Z, Ramsey L, Nader F, et al. Health-related quality of life in patients with chronic hepatitis B. Liver Int. 2007;27(8):1119-25.

13. Dan AA, Kallman JB, Wheeler A, Younoszai Z, Collantes R, Bondini $\mathrm{S}$, et al. Health-related quality of life in patients with non-alcoholic fatty liver disease. Aliment Pharmacol Ther. 2007;26(6):815-20.

14. Forton DM, Allsop JM, Main J, Foster GR, Thomas HC, Taylor-Robinson SD. Evidence for a cerebral effect of the hepatitis $C$ virus. Lancet. 2001;358(9275):38-9.

15. Forton DM, Thomas HC, Murphy CA, Allsop JM, Foster GR, Main $J$, et al. Hepatitis $C$ and cognitive impairment in a cohort of patients with mild liver disease. Hepatology. 2002;35(2):433-9.

16. Forton DM, Allsop JM, Cox IJ, Hamilton G, Wesnes K, Thomas $\mathrm{HC}$, et al. A review of cognitive impairment and cerebral metabolite abnormalities in patients with hepatitis $\mathrm{C}$ infection. AIDS. 2005;19 Suppl 3:S53-63.

17. Forton DM, Taylor-Robinson SD, Thomas HC. Cerebral dysfunction in chronic hepatitis C infection.J Viral Hepat. 2003;10(2):81-6.

18. Hilsabeck RC, Perry W, Hassanein TI. Neuropsychological impairment in patients with chronic hepatitis C. Hepatology. 2002;35(2):440-6.

19. Kramer L, Hofer H, Bauer E, Funk G, Formann E, Steindl-Munda P, et al. Relative impact of fatigue and subclinical cognitive brain dysfunction on health-related quality of life in chronic hepatitis C infection. AIDS. 2005;19 Suppl 3:S85-92.

20. Bownik H, Saab S. The effects of hepatitis C recurrence on health-related quality of life in liver transplant recipients. Liver Int. 2010;30(1):19-30.

21. Poynard T, Cacoub P, Ratziu V, Myers RP, Dezailles MH, Mercadier A, et al. Fatigue in patients with chronic hepatitis C. J Viral Hepat. 2002;9(4):295-303.

22. Seaman K, Paterson BL, Vallis M, Hirsch G, Peltekian KM. Future directions for investigation of fatigue in chronic hepatitis $C$ viral infection. Chronic Illn. 2009;5(2):115-28.

23. Racciatti D, Gorgoretti V, Sepede G, Gambi F, Pizzigallo E. An Italian study on health-related quality of life and fatigue in patients with chronic fatigue syndrome and patients with chronic HCV virus infection: similarities and differences. Int J Immunopathol Pharmacol. 2011;24(3):673-81.

24. Barkhuizen A, Rosen HR, Wolf S, Flora K, Benner K, Bennett RM. Musculoskeletal pain and fatigue are associated with chronic hepatitis C: a report of 239 hepatology clinic patients. Am J Gastroenterol.1999;94(5):1355-60.

25. Hilsabeck RC, Hassanein TI, Perry W. Biopsychosocial predictors of fatigue in chronic hepatitis C.J Psychosom Res. 2005;58(2):173-8.

26. Anty R, Marjoux S, Bekri S, DeGalleani L, Dainese R, Gelsi E, et al. Plasma carnitine is associated with fatigue in chronic hepatitis C but not in the irritable bowel syndrome. Aliment Pharmacol Ther. 2011;33(8):961-8.
27. El-Gindy EM, Ali-Eldin FA, Meguid MA. Serum leptin level and its association with fatigue in patients with chronic hepatitis $\mathrm{C}$ virus infection. Arab J Gastroenterol. 2012;13(2):54-7.

28. Sarkar S, Jiang Z, Evon DM, Wahed AS, Hoofnagle JH. Fatigue before, during and after antiviral therapy of chronic hepatitis C: Results from the Virahep-C study.J Hepatol. 2012;57(5):946-52.

29. Felger JC, Alagbe O, Pace TW, Woolwine BJ, Hu F, Raison CL, et al. Early activation of p38 mitogen activated protein kinase is associated with interferon-alpha-induced depression and fatigue. Brain Behav Immun. 2011;25(6):1094-8.

30. Felger JC, Cole SW, Pace TW, Hu F, Woolwine BJ, Doho GH, et al. Molecular signatures of peripheral blood mononuclear cells during chronic interferon-alpha treatment: relationship with depression and fatigue. Psychol Med. 2012;42(8):1591-603.

31. Kronenberger B, Berg T, Herrmann E, Hinrichsen H, Gerlach T, Buggisch P, et al. Efficacy of amantadine on quality of life in patients with chronic hepatitis $C$ treated with interferon-alpha and ribavirin: results from a randomized, placebo-controlled, double-blind trial. Eur J Gastroenterol Hepatol. 2007;19(8):639-46.

32. Malaguarnera M, Vacante M, Bertino G, Neri S, Gargante MP, Motta $\mathrm{M}$, et al. The supplementation of acetyl-L-carnitine decreases fatigue and increases quality of life in patients with hepatitis $C$ treated with pegylated interferon-alpha $2 \mathrm{~b}$ plus ribavirin. J Interferon Cytokine Res. 2011;31(9):653-9.

33. Martin KA, Krahn LE, Balan V, Rosati MJ. Modafinil's use in combating interferon-induced fatigue. Dig Dis Sci. 2007;52(4):893-6.

34. Rabkin JG, McElhiney MC, Rabkin R. Modafinil and armodafinil treatment for fatigue for HIV-positive patients with and without chronic hepatitis C. Int J STD AIDS. 2011;22(2):95-101.

35. Goulding C, O'Connell P, Murray FE. Prevalence of fibromyalgia anxiety and depression in chronic hepatitis $C$ virus infection: relationship to RT-PCR status and mode of acquisition. Eur J Gastroenterol Hepatol. 2001;13(5):507-11.

36. Kozanoglu E, Canataroglu A, Abayli B, Colakoglu S, Goncu K. Fibromyalgia syndrome in patients with hepatitis $\mathrm{C}$ infection. Rheumatol Int. 2003;23(5):248-51.

37. Mohammad A, Carey JJ, Storan E, Scarry M, Coughlan RJ, Lee JM. Prevalence of fibromyalgia among patients with chronic hepatitis C infection: relationship to viral characteristics and quality of life. J Clin Gastroenterol. 2012;46(5):407-12.

38. Mohammed RH, ElMakhzangy HI, Gamal A, Mekky F, El Kassas M, Mohammed N, et al. Prevalence of rheumatologic manifestations of chronic hepatitis $\mathrm{C}$ virus infection among Egyptians. Clin Rheumatol. 2010;29(12):1373-80.

39. Morasco BJ, Huckans M, Loftis JM, Woodhouse J, Seelye A, Turk DC et al. Predictors of pain intensity and pain functioning in patients with the hepatitis C virus. Gen Hosp Psychiatry. 2010;32(4):413-8.

40. Rifai MA, Indest D, Loftis J, Hauser P. Psychiatric management of the hepatitis C patient. Curr Treat Options Gastroenterol. 2006;9(6):508-19.

41. Schaefer M, Capuron L, Friebe A, Diez-Quevedo C, Robaeys G, Neri $S$, et al. Hepatitis $C$ infection, antiviral treatment and Mental Health: A European Expert Consensus Statement. J Hepatol. 2012; 57(6):1379-90

42. Rifai MA, Gleason OC, Sabouni D. Psychiatric care of the patient with hepatitis C: a review of the literature. Prim Care Companion J Clin Psychiatry. 2010;12(6).

43. McMahon JM, Tortu S. A potential hidden source of hepatitis $\mathrm{C}$ infection among noninjecting drug users. J Psychoactive Drugs. 2003;35(4):455-60.

44. el-Serag HB, Kunik M, Richardson P, Rabeneck L. Psychiatric disorders among veterans with hepatitis $\mathrm{C}$ infection. Gastroenterology. 2002;123(2):476-82.

45. Fontana RJ, Hussain KB, Schwartz SM, Moyer CA, Su GL, Lok AS. Emotional distress in chronic hepatitis $\mathrm{C}$ patients not receiving antiviral therapy. J Hepatol. 2002;36(3):401-7.

46. Zickmund S, Hillis SL, Barnett MJ, Ippolito L, LaBrecque DR. Hepatitis $\mathrm{C}$ virus-infected patients report communication problems with physicians. Hepatology. 2004;39(4):999-1007.

47. Gitto S, Micco L, Conti F, Andreone P, Bernardi M. Alcohol and viral hepatitis: a mini-review. Dig Liver Dis. 2009;41(1):67-70.

48. Raison CL, Demetrashvili M, Capuron L, Miller AH. Neuropsychi- 
atric adverse effects of interferon-alpha: recognition and management. CNS Drugs. 2005;19(2):105-23.

49. Ping F, Shang J, Zhou J, Zhang H, Zhang L. 5-HT(1A) receptor and apoptosis contribute to interferon-alpha-induced "depressivelike" behavior in mice. Neurosci Lett. 2012;514(2):173-8.

50. Kenis G, Prickaerts J, van Os J, Koek GH, Robaeys G, Steinbusch HW et al. Depressive symptoms following interferon-alpha therapy: mediated by immune-induced reductions in brain-derived neurotrophic factor? Int J Neuropsychopharmacol. 2011;14(2):247-53.

51. Udina M, Castellvi P, Moreno-Espana J, Navines R, Valdes M, Forns $\mathrm{X}$, et al. Interferon-induced depression in chronic hepatitis C: a systematic review and meta-analysis. J Clin Psychiatry. 2012;73(8):1128-38.

52. McNutt MD, Liu S, Manatunga A, Royster EB, Raison CL, Woolwine $B$ J, et al. Neurobehavioral effects of interferon-alpha in patients with hepatitis-C: symptom dimensions and responsiveness to paroxetine. Neuropsychopharmacology. 2012;37(6):1444-54.

53. Baraldi S, Hepgul N, Mondelli V, Pariante CM. Symptomatic treatment of interferon-alpha-induced depression in hepatitis C: a systematic review. J Clin Psychopharmacol. 2012;32(4):531-43.

54. Kelly EM, Corace K, Emery J, Cooper CL. Bipolar patients can safely and successfully receive interferon-based hepatitis $C$ antiviral treatment. Eur J Gastroenterol Hepatol. 2012;24(7):811-6.

55. Sheridan DA, Price DA, Schmid ML, Toms GL, Donaldson P, Neely $\mathrm{D}$, et al. Apolipoprotein B-associated cholesterol is a determinant of treatment outcome in patients with chronic hepatitis $C$ virus infection receiving anti-viral agents interferon-alpha and ribavirin. Aliment Pharmacol Ther. 2009;29(12):1282-90.

56. Navines R, Castellvi P, Moreno-Espana J, Gimenez D, Udina M Canizares $\mathrm{S}$, et al. Depressive and anxiety disorders in chronic hepatitis $C$ patients: reliability and validity of the Patient Health Questionnaire.J Affect Disord. 2012;138(3):343-51.

57. Sockalingam S, Abbey SE, Alosaimi F, Novak M. A review of sleep disturbance in hepatitis C. J Clin Gastroenterol. 2010;44(1):38-45.

58. Sockalingam S, Shammi C, Stergiopoulos V. Managing the neuropsychiatric complications of hepatitis C treatment. BrJ Hosp Med (Lond). 2007;68(10):520-5.

59. Fletcher NF, McKeating JA. Hepatitis C virus and the brain. J Viral Hepat. 2012;19(5):301-6.

60. Hilsabeck RC, Hassanein TI, Carlson MD, Ziegler EA, Perry W. Cognitive functioning and psychiatric symptomatology in patients with chronic hepatitis C. J Int Neuropsychol Soc. 2003;9(6):847-54.

61. Weissenborn K, Krause J, Bokemeyer M, Hecker H, Schuler A, Ennen JC, et al. Hepatitis $C$ virus infection affects the brain-evidence from psychometric studies and magnetic resonance spectroscopy. J Hepatol. 2004;41(5):845-51.

62. Huckans M, Seelye A, Woodhouse J, Parcel T, Mull L, Schwartz D, et al. Discounting of delayed rewards and executive dysfunction in individuals infected with hepatitis C.J Clin Exp Neuropsy chol. 2011:33(2):176-86.

63. Kramer L, Bauer E, Funk G, Hofer H, Jessner W, Steindl-Munda P, et al. Subclinical impairment of brain function in chronic hepatitis C infection. J Hepatol. 2002;37(3):349-54.

64. Perry W, Hilsabeck RC, Hassanein TI. Cognitive dysfunction in chronic hepatitis C: a review. Dig Dis Sci. 2008;53(2):307-21.

65. Quarantini LC, Miranda-Scippa A, Batista-Neves S, Powell VB, Abreu N, Abreu KC, et al. A neuropsychological study comparing patients infected with HCV and HBV without psychiatric comorbidities. J Med Virol. 2009;81(7):1184-8.

66. Lowry D, Coughlan B, McCarthy O, Crowe J. Investigating healthrelated quality of life, mood and neuropsychological test performance in a homogeneous cohort of Irish female hepatitis $\mathrm{C}$ patients. J Viral Hepat. 2010;17(5):352-9.

67. Rodrigue JR, Balistreri W, Haber B, Jonas MM, Mohan P, Molleston $\mathrm{JP}$, et al. Impact of hepatitis $\mathrm{C}$ virus infection on children and their caregivers: quality of life, cognitive, and emotional outcomes. J Pediatr Gastroenterol Nutr. 2009;48(3):341-7.

68. Fontana RJ, Bieliauskas LA, Back-Madruga C, Lindsay KL, Litman HJ, Lok AS, et al. Cognitive function does not worsen during longterm low-dose peginterferon therapy in patients with chronic hepatitis C. Am J Gastroenterol. 2010;105(7):1551-60.

69. Byrnes V, Miller A, Lowry D, Hill E, Weinstein C, Alsop D, et al. Ef- fects of anti-viral therapy and HCV clearance on cerebral metabolism and cognition. J Hepatol. 2012;56(3):549-56.

70. Monaco S, Ferrari S, Gajofatto A, Zanusso G, Mariotto S. HCV-Related Nervous System Disorders. Clin Dev Immunol. 2012;2012:236148.

71. Pattullo V, McAndrews MP, Damyanovich A, Heathcote EJ. Influence of hepatitis $C$ virus on neurocognitive function in patients free from other risk factors: validation from therapeutic outcomes. Liver Int. 2011;31(7):1028-38.

72. Weissenborn K, Ennen JC, Bokemeyer M, Ahl B, Wurster U, Tillmann $\mathrm{H}$, et al. Monoaminergic neurotransmission is altered in hepatitis $\mathrm{C}$ virus infected patients with chronic fatigue and cognitive impairment. Gut. 2006;55(11):1624-30.

73. Martin-Thormeyer EM, Paul RH. Drug abuse and hepatitis C infection as comorbid features of HIV associated neurocognitive disorder: neurocognitive and neuroimaging features. Neuropsychol Rev. 2009;19(2):215-31.

74. Crystal H, Kleyman I, Anastos K, Lazar J, Cohen M, Liu C, et al. Effects of hepatitis $\mathrm{C}$ and HIV on cognition in women: data from the Women's Interagency HIV Study. J Acquir Immune Defic Syndr. 2012;59(2):149-54.

75. Blacklaws H, Gardner A, Usher K. Irritability: an underappreciated side effect of interferon treatment for chronic hepatitis $\mathrm{C}$ ? Clin Nurs. 2011;20(9-10):1215-24

76. Lotrich FE, Ferrell RE, Rabinovitz M, Pollock BG. Labile anger during interferon alfa treatment is associated with a polymorphism in tumor necrosis factor alpha. Clin Neuropharmacol. 2010;33(4):191-7.

77. Bezemer G, Van Gool AR, Fekkes D, Vrolijk JM, Hansen BE, Janssen $\mathrm{HL}$, et al. Psychiatric side effects and fluctuations in serotonergic parameters in the treatment of chronic hepatitis $\mathrm{C}$ infection. Neuropsychobiology. 2012;65(3):126-32.

78. Butt G. Stigma in the context of hepatitis C: concept analysis. $J$ Adv Nurs. 2008;62(6):712-24.

79. Butt G, Paterson BL, McGuinness LK. Living with the stigma of hepatitis C. West J Nurs Res. 2008;30(2):204-21.

80. Zickmund S, Ho EY, Masuda M, Ippolito L, LaBrecque DR. "They treated me like a leper". Stigmatization and the quality of life of patients with hepatitis C. J Gen Intern Med. 2003;18(10):835-44.

81. Golden J, Conroy RM, O'Dwyer AM, Golden D, Hardouin JB. Illness-related stigma, mood and adjustment to illness in persons with hepatitis C. Soc Sci Med. 2006;63(12):3188-98.

82. Grundy G, Beeching N. Understanding social stigma in women with hepatitis C. Nurs Stand. 2004;19(4):35-9.

83. Schafer A, Scheurlen M, Felten M, Kraus MR. Physician-patient relationship and disclosure behaviour in chronic hepatitis $\mathrm{C}$ in a group of German outpatients. Eur J Gastroenterol Hepatol. 2005;17(12):1387-94.

84. Moore GA, Hawley DA, Bradley P. Hepatitis C: studying stigma. Gastroenterol Nurs. 2008;31(5):346-52.

85. Moore GA, Hawley DA, Bradley P. Hepatitis C: experiencing stigma. Gastroenterol Nurs. 2009;32(2):94-104.

86. Kraus MR, Schafer A, Csef H, Scheurlen M, Faller H. Emotional state, coping styles, and somatic variables in patients with chronic hepatitis C. Psychosomatics. 2000;41(5):377-84

87. Grassi L, Satriano J, Serra A, Biancosino B, Zotos S, Sighinolfi L, et al. Emotional stress, psychosocial variables and coping associated with hepatitis $C$ virus and human immunodeficiency virus infections in intravenous drug users. Psychother Psychosom. 2002;71(6):342-9.

88. Sanyal C, Ingram EL, Sketris IS, Peltekian KM, Kirkland S. Coping strategies used by patients infected with hepatitis $C$ virus who are facing medication costs. Can J Hosp Pharm. 2011;64(2):131-40.

89. Treloar C, Hopwood M. "Look, I'm fit, I'm positive and I'll be all right, thank you very much": coping with hepatitis C treatment and unrealistic optimism. Psychol Health Med. 2008:13(3):360-6.

90. Blasiole JA, Shinkunas L, Labrecque DR, Arnold RM, Zickmund SL. Mental and physical symptoms associated with lower social support for patients with hepatitis C. World J Gastroenterol. 2006;12(29):4665-72.

91. Evon DM, Esserman DA, Ramcharran D, Bonner JE, Fried MW. Social support and clinical outcomes during antiviral therapy for chronic hepatitis C. J Psychosom Res. 2011;71(5):349-56. 
92. Evon DM, Ramcharran D, Belle SH, Terrault NA, Fontana RJ, Fried MW. Prospective analysis of depression during peginterferon and ribavirin therapy of chronic hepatitis C: results of the Virahep-C study. Am J Gastroenterol. 2009;104(12):2949-58.

93. Rowan PJ, Al-Jurdi R, Tavakoli-Tabasi S, Kunik ME, Satrom SL, ElSerag HB. Physical and psychosocial contributors to quality of life in veterans with hepatitis $C$ not on antiviral therapy. J Clin Gastroenterol. 2005;39(8):731-6.

94. Cormier M. The role of hepatitis C support groups. Gastroenterol Nurs. 2005;28(3 Suppl):S4-9.

95. Edlin BR, Kresina TF, Raymond DB, Carden MR, Gourevitch MN, Rich JD, et al. Overcoming barriers to prevention, care, and treatment of hepatitis C in illicit drug users. Clin Infect Dis. 2005;40 Suppl 5:S276-85.

96. Loftis JM, Matthews AM, Hauser P. Psychiatric and substance use disorders in individuals with hepatitis C: epidemiology and management. Drugs. 2006;66(2):155-74.
97. Khokhar OS, Lewis JH. Reasons why patients infected with chronic hepatitis $C$ virus choose to defer treatment: do they alter their decision with time? Dig Dis Sci. 2007;52(5):1168-76.

98. Hatem C, Minello A, Bresson-Hadni S, Jooste V, Evrard P, Obert B, et al. Is the management of hepatitis $C$ patients appropriate? A population-based study. Aliment Pharmacol Ther. 2005;21(8):1007 15.

99. Jecker NS. Caring for "socially undesirable" patients. Camb Q Healthc Ethics. 1996;5(4):500-10.

100. Lang JP, Michel L, Melin P, Schoeffler M, Gauchet A, Rousseaux C, et al. Management of psychiatric disorders and addictive behaviors in patients with viral hepatitis $\mathrm{C}$ in France. Gastroenterol Clin Biol. 2009;33(1 Pt 1):1-7.

101. Knott A, Dieperink E, Willenbring ML, Heit S, Durfee JM, Wingert $\mathrm{M}$, et al. Integrated psychiatric/medical care in a chronic hepatitis C clinic: effect on antiviral treatment evaluation and outcomes. Am J Gastroenterol. 2006;101(10):2254-62. 